\title{
Dopamine Agonists: Time Pattern of Adverse Effects Reporting in Australia
}

\author{
Samantha A. Hollingworth ${ }^{1}$ - Treasure M. McGuire Mand $^{1,3, \text { David Pache }^{1,3,4}}$. \\ Mervyn J. Eadie ${ }^{2}$
}

Published online: 16 July 2015

(c) The Author(s) 2015. This article is published with open access at Springerlink.com

\begin{abstract}
Background In Australia, there is voluntary reporting of suspected adverse events (AEs) of therapeutic medicines. Some dopamine agonists (DAs) have serious AEs.

Objective We aimed to explore the pattern of DA AE reporting over two decades.

Methods We analysed AE case line listings obtained from the Australian Committee on the Safety of Medicines (ACSOM) for bromocriptine, cabergoline, pergolide, pramipexole and ropinirole, and related these to drug utilisation data (1992-2012). We noted the AE nature, frequency, onset, novelty, severity and outcome.

Results The 220 suspected AEs fell into five categories: (i) syncopal/pre-syncopal, (ii) fibrotic, (iii) psychotic, (iv) obsessive-compulsive behaviours (OCB) and (v) increased sleep. There were differential lag times between initial individual drug registration and reporting of suspected
\end{abstract}

Samantha A. Hollingworth

s.hollingworth@uq.edu.au

Treasure M. McGuire

t.mcguire@uq.edu.au

David Pache

d.pache@uq.edu.au

Mervyn J. Eadie

m.eadie@uq.edu.au

1 School of Pharmacy, The University of Queensland, 20 Cornwall St, Woolloongabba, QLD 4102, Australia

2 School of Medicine, The University of Queensland, 288 Herston Rd, Herston, QLD 4006, Australia

3 Mater Pharmacy Services, Mater Health Services, Raymond Tce, South Brisbane, QLD 4101, Australia

4 Faculty of Health, Sciences and Medicine, Bond University, Gold Coast, QLD 4229, Australia
AEs, with a lag of at least one year for fibrotic reactions and OCB compared to more contemporaneous reporting of other AEs. Consistent with the published literature, ACSOM data showed that ergot DAs share fibrotic reactions as a class $\mathrm{AE}$, whereas symptomatic hypotensive reactions, psychosis and OCB occurred in both ergot and non-ergot DAs, cabergoline and pramipexole, respectively. Reports of syncopal and pre-syncopal reactions seemed to diminish as ergot-based DA use declined. Levodopa was taken simultaneously with DAs in 87 instances. Of those treated, $92 \%$ were 50 years or older. Parkinson's disease accounted for $89 \%$ of use (119 reports).

Conclusions Exploring the temporal relationship between post-marketing $\mathrm{AE}$ reporting and utilisation data, as exemplified by DAs, can be a valuable pharmacovigilance tool to encourage targeted adverse event monitoring and reporting.

\section{Key Points}

The pattern of adverse event reporting of dopamine agonists (DAs) in Australia was previously unknown.

Ergot DAs shared fibrotic reactions as a class adverse effect (AE), whereas symptomatic hypotensive reactions, psychosis and obsessivecompulsive behaviours occurred in both ergot and non-ergot DAs.

Exploring the temporal relationship between postmarketing AE reporting and utilisation data can be a valuable pharmacovigilance tool to encourage targeted adverse event monitoring and reporting. 


\section{Introduction}

Dopamine agonists (DAs) can be broadly subdivided into ergot derivatives (e.g. bromocriptine, cabergoline, pergolide) and non-ergot derivatives (ropinirole, pramipexole, apomorphine and rotigotine. While effective in the control of Parkinson's disease, their use has recently decreased in Australia [1], probably reflecting caution after unusual adverse effects with ergot-derived DAs were reported. These include abrupt onset of sleep in inappropriate circumstances [2-4], compulsive behaviours [5-7] and fibrotic reactions [8-10]. The former Australian Adverse Drug Reaction Bulletin reported on pathological gambling with cabergoline in 2005 [11] and fibrotic reactions with ergot derivatives in 2006 [12]. In 2007, the US Food and Drug Administration issued a Public Health Advisory for pergolide, which was withdrawn from the US market shortly afterward [13]. Such unfavourable press has probably contributed to increased use of the recently available non-ergot DA, pramipexole. Directly acting DAs were registered for use in Australia by the Therapeutic Goods Administration (TGA) from the 1990s: bromocriptine (pre1992), pergolide (1994), cabergoline (2000), rotigotine (2007), ropinirole (2008) and pramipexole (2008). Although comparison of AEs associated with DAs have been evaluated elsewhere [7, 14, 15], there have been no published studies of post-marketing adverse events (AEs) across the class of dopamine agonists in Australia. We aimed to explore the pattern of $\mathrm{AE}$ reporting of DAs received by Australian regulatory authorities.

\section{Methods}

A voluntary post-marketing mechanism exists whereby health professionals and consumers may report suspected adverse effects of therapeutic medicines to the Australian Committee on the Safety of Medicines (ACSOM), part of the TGA in the Australian Government Department of Health. The TGA maintains the Database of Adverse Event Notifications (DAEN: http://www.tga.gov.au/daen/daenentry.aspx). We analysed the de-identified DAEN case details for bromocriptine, cabergoline, pergolide, pramipexole and ropinirole-the most widely used directly acting DAs in Australia from 1992 to 2012. As the cost of rotigotine prescriptions was only subsidised from May 2013 (outside the study period) and reports of AEs were low; this medicine was excluded from review. There was also too little apomorphine use to warrant consideration. AE reports may contain data on: date of event, sex, age, outcome (recovered or not), polypharmacy, onset time and (nature of) reaction; however, information supplied is sometimes incomplete. We were not able to access any information on dose for reported medicines.

Pharmacovigilance data for included DAs were related to drug utilisation data for the same period (2002-2012). DA use was reported as annual dispensed prescriptions under the Pharmaceutical Benefits (PBS) or Repatriation Pharmaceutical Benefits (RPBS) Schemes and from estimated non-subsidised (i.e. under general co-payment and private) prescribing. As ropinirole is not subsidised by these Schemes and available only on private prescription, use was low during the study period. It was therefore excluded from utilisation review. Patterns of adverse reaction reporting were related to annual use of individual agonists. Although bromocriptine was available in Australia prior to 1992, we could not access AE reports before that time.

\section{Results}

A considerable variety of possible adverse effects was reported. Here only the more common (ten or more instances) and novel reactions are considered. They fall into five main categories: (i) syncopal or pre-syncopal (i.e. hypotensive); (ii) fibrotic (lung, pleura ( \pm effusion), pericardium, abdominal cavity and retroperitoneal, heart valves); (iii) psychotic (including hallucinations, confusion); (iv) obsessive-compulsive behaviours (OCBs; pathological gambling, hypersexuality, punding [16]; and (v) increased sleep (somnolence, abrupt onset sleep). There were 220 reports of such adverse reactions between 1992 and 2012 (Table 1). It should be noted that a single AE report may have involved more than one symptom and that two DAs were co-administered in eight reports. Consequently, total report numbers and numbers of individual adverse effects do not reconcile. Levodopa was taken simultaneously with DAs in 87 instances. The patient's age was recorded in 83 of these 87 , with $92 \%$ being 50 years or older and, of 78 cases, $33 \%$ were female. In contrast, of the 102 patients not taking levodopa whose ages were recorded, $67 \%$ were 50 years or older. The indications for which the medicines had been used were noted in 119 of these reports: Parkinson's disease, 106; restless legs, four; and endocrine purposes including lactation suppression, nine.

In the 1990s, bromocriptine was the dominant DA and pergolide use was low (Fig. 1, upper panel). From a peak in the early 1990s, bromocriptine prescriptions declined steadily. Cabergoline use peaked in the mid-2000s, but then decreased as pramipexole was introduced in 2007 and its use thereafter increased dramatically. Ropinirole nonsubsidised use was very low, and constituted about two- 
Table 1 Reported adverse effects in two classes (ergot and non-ergot derivatives) and five main categories associated with dopamine agonists

\begin{tabular}{|c|c|c|c|c|c|c|c|c|c|c|}
\hline \multirow[t]{3}{*}{ Adverse effects } & \multicolumn{6}{|c|}{ Ergot derivatives } & \multicolumn{4}{|c|}{ Non-ergot derivatives } \\
\hline & \multicolumn{2}{|c|}{$\begin{array}{l}\text { Bromocriptine } \\
N=62\end{array}$} & \multicolumn{2}{|c|}{$\begin{array}{l}\text { Pergolide } \\
N=29\end{array}$} & \multicolumn{2}{|c|}{$\begin{array}{l}\text { Cabergoline } \\
N=95\end{array}$} & \multicolumn{2}{|c|}{$\begin{array}{l}\text { Pramipexole } \\
N=29\end{array}$} & \multicolumn{2}{|c|}{$\begin{array}{l}\text { Ropinirole }^{\mathrm{a}} \\
N=12\end{array}$} \\
\hline & $n$ & $\%$ & $n$ & $\%$ & $n$ & $\%$ & $n$ & $\%$ & $N$ & $\%$ \\
\hline Hypotension & 17 & 27 & 7 & 24 & 6 & 6 & 2 & 7 & 4 & 33 \\
\hline Fibrosis & 15 & 24 & 6 & 21 & 26 & 27 & 0 & 0 & 0 & 0 \\
\hline Psychosis & 28 & 45 & 7 & 24 & 26 & 27 & 24 & 83 & 4 & 33 \\
\hline Obsessive-compulsive behaviour & 0 & 0 & 4 & 14 & 32 & 34 & 5 & 17 & 3 & 25 \\
\hline Sleep excess & 2 & 3 & 2 & 7 & 4 & 4 & 2 & 7 & 0 & 0 \\
\hline
\end{tabular}

${ }^{a}$ Ropinirole was not subsidised during the study period
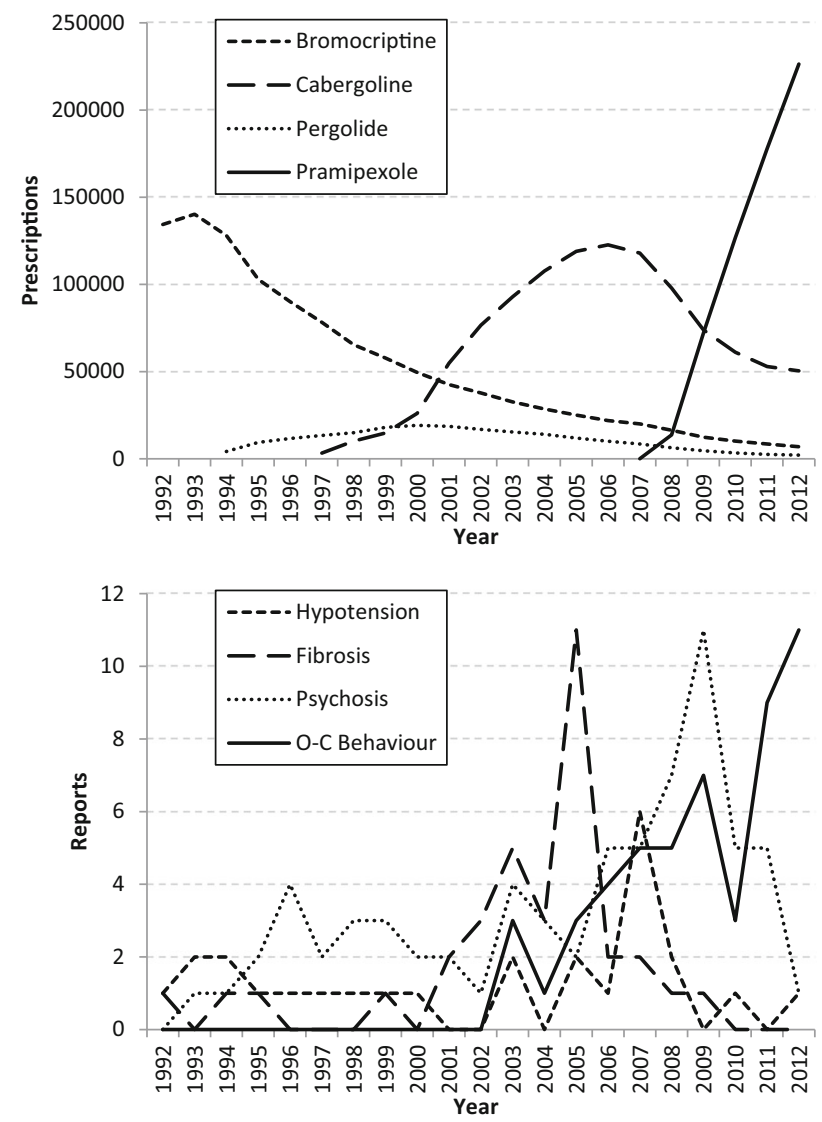

Fig. 1 Use of dopamine agoninsts (DAs) and frequency of reported adverse effects between 1992 and 2012. Upper panel dispensed prescriptions of bromocriptine, pergolide, cabergoline and pramipexole. Lower panel reports of DAs associated with hypotension, fibrosis, psychotic disturbances and obsessive-compulsive behaviours [ropinirole was not subsidised during the study period]

thirds of pergolide subsidised and non-subsidised use in the period 2008-2010.

There was a general increase in the reporting of AEs over time (Fig. 1, lower panel). Reports of hypotension remained low and stable during the 1990s, peaked in 2007, and then quickly declined, coinciding with pramipexole replacing cabergoline use. Reports of OCB AEs began in 2003 and, apart from two dips (2004 and 2010), increased to a peak in 2012. This coincides with peaking cabergoline and then pramipexole use. Psychotic reactions peaked in 2009 then declined, which correlated with decreased cabergoline and increased pramipexole use. The association of long-term therapy with ergot-derived DAs and fibrotic reactions is well recognised [17-19], with a peak of reports in 2005 and subsequent decline. It is difficult to determine whether the fewer reports reflect the steady decline in prescribing of bromocriptine since the 1990s, or cabergoline, or both. Fibrotic reactions tend to take several years to manifest. Thus, this association probably prompted the decline of bromocriptine and cabergoline prescribing (pergolide use being already significantly less than the others), and may have promoted the rapid growth of pramipexole use.

With regard to reaction onset, $77 \%$ of hypotensive problems occurred within the first week of DA therapy, whereas $67 \%$ of fibrotic reactions were not recognised until at least one year after therapy initiation. Some $34 \%$ of the psychotic reactions occurred in the initial week of medicine intake, and $54 \%$ within the first month; however, $15 \%$ took more than a year to be recognised. OCB AEs was noted within the first 6 months for only $25 \%$; in half, the medicines had been used for at least one year. Sleep disturbances were too infrequent to warrant further consideration, but we noted there were five instances of abruptonset sleep-three associated with cabergoline, one with pergolide and one with pramipexole.

There appears to be an under-reporting of levodopa cotherapy in the reports. Use of DA monotherapy for endocrine disorders is likely to be small. For example, lactation suppression would only account for a few days of low dose use. The long-term use of DAs as sole therapy for prolactinoma is also rare compared to their use in movement disorders. This case recording anomaly is supported by two-thirds of the reported DA monotherapy patients being in the Parkinsonian age group (i.e. 50+ years), with ages 
un-recorded in $4.6 \%$ of those reported as taking levodopa, but in $12.7 \%$ of those not taking it. Hence, the role of dopamine formed from levodopa in contributing to adverse effects cannot be elucidated from these data.

\section{Discussion}

Although reporting rates have increased over time; only a small proportion of AEs are actually reported to national reporting centres [20]. Under-reporting appears to be a consistent concern for studies in pharmacovigilance [15]. In an attempt to improve transparency and offset the low reporting rates from health professionals, Australian consumers have been recognised as active partners in pharmacovigilance since 2000. The TGA report options include mailing a 'blue card' or using the web link (https://www. ebs.tga.gov.au/ebs/ADRS/ADRSRepo.nsf?OpenDatabase) or the national consumer Adverse Medicine Events (AME) Line [21]. Despite these options, there remains not only low awareness of available reporting systems but also limited promotion on how to use them [22].

There were differential lag times between the individual DA being marketed and reporting of individual suspected AEs: at least one year for fibrotic reactions and OCBs, whereas the other adverse effects appear to be more contemporaneous. Fibrotic reactions appear to be class-type AEs of ergot-derived DAs, whereas symptomatic hypotensive reactions, psychosis and OCBs have occurred in both an ergot and a non-ergot DA (cabergoline and pramipexole, respectively). Although these data appear plausible and consonant with clinical experience, at least two questions arise.

Firstly, how representative of the true situation in the community are these data? Analysis and commentary of AE reporting depends on the initiative of individual practitioners, patients and others concerned with patient welfare. There is likely to be disproportionate reporting of AEs that appear novel or dangerous to the patient [23-25]. Publicity about a newly recognised and perhaps surprising $\mathrm{AE}$, such as pathological gambling or abruptly falling asleep in potentially hazardous situations, is likely to encourage reporting. In contrast, subsequent familiarity with such AEs may reduce the motivation to report. It is impossible to know, from the available data, whether the decrease in reporting of psychotic behaviour associated with pramipexole can be explained by disproportionate under-reporting or a low incidence of occurrence of this AE. This alludes to the 'notoriety bias' which was also identified by Pariente et al. [26], i.e. the increased reporting of AEs following safety alerts.

Secondly, is cabergoline the only medication among the ergot-based DAs associated with OCBs? Such behaviours may have been too rare to be recognised as medicine-related for the older ergot-based agonists. They may have been reported disproportionately when their nature and relation to the therapeutic class were identified.

There is also uncertainty about the possible added effects of dopamine derived from co-administered levodopa in a number of cases. Despite the limitations in the data, the AE profile of the non-ergot pramipexole appeared to differ from those of the ergot-based DAs.

Consistent with the published literature, these data showed that ergot DAs share fibrotic reactions as a class AE. The remaining categories of AEs relate to individual medicines rather than a subclass. Unfortunately, the relatively low number of $\mathrm{AE}$ reports submitted for DAs in Australia precluded further sub-group analysis. Exploring the relationship between post-marketing $\mathrm{AE}$ reporting and utilisation data, as exemplified by DAs, can be a valuable pharmacovigilance tool. Individual AEs with medicines within a therapeutic class appear to have differential lag times between the medicine being marketed and suspicion of a causal link. Contributing factors include the inherent nature of the $\mathrm{AE}$, reaction novelty and severity, and frequency of medicine use. This time lag also appears to differ for subjective versus objectively measurable symptoms and signs. Prospective consideration of likely temporal reporting patterns across individual medicines and therapeutic classes could, however, contribute to risk reduction by proactive encouragement of monitoring and reporting of AEs when such events are most likely to manifest.

Acknowledgments Data in the paper were provided by the Therapeutic Goods Administration's (TGA) Australian Committee on the Safety of Medicines (ACSOM) and the Drug Utilisation Sub-Committee (DUSC), Pharmaceutical Benefits Branch, Pharmaceutical Benefits Division, Australian Government Department of Health and Ageing. We acknowledge the research assistance of Ms Amanda Rush.

\section{Compliance with Ethical Standards}

Funding This study was funded from existing salaries. This research received no specific grant from any funding agency in the public, commercial or not-for-profit sectors.

Conflict of interest The authors Dr. Hollingworth, Assoc. Prof. McGuire, Dr. Pache and Emer. Prof. Eadie declare that there were no conflicts of interest.

Ethical approval No ethical approval was required as we used only secondary de-identified data sources.

Open Access This article is distributed under the terms of the Creative Commons Attribution-NonCommercial 4.0 International License (http://creativecommons.org/licenses/by-nc/4.0/), which permits any noncommercial use, distribution, and reproduction in any medium, provided you give appropriate credit to the original author(s) and the source, provide a link to the Creative Commons license, and indicate if changes were made. 


\section{References}

1. Hollingworth SA, Rush A, Hall WD, Eadie MJ. Utilization of anti-Parkinson drugs in Australia: 1995-2009. Pharmacoepidemiol Drug Saf. 2011;20(5):450-6.

2. Etminan M, Samii A, Takkouche B, Rochon PA. Increased risk of somnolence with the new dopamine agonists in patients with Parkinson's disease: a meta-analysis of randomised controlled trials. Drug Saf. 2001;24(11):863-8.

3. Homann CN, Wenzel K, Suppan K, Ivanic G, Kriechbaum N, Crevenna $\mathrm{R}$, et al. Sleep attacks in patients taking dopamine agonists: review. BMJ. 2002;324(7352):1483-7.

4. Knie B, Mitra MT, Logishetty K, Chaudhuri KR. Excessive daytime sleepiness in patients with Parkinson's disease. CNS Drugs. 2011;25(3):203-12.

5. Antonini A, Cilia R. Behavioural adverse effects of dopaminergic treatments in Parkinson's disease: incidence, neurobiological basis, management and prevention. Drug Saf. 2009;32(6):475-88.

6. Lader M. Antiparkinsonian medication and pathological gambling. CNS Drugs. 2008;22(5):407-16.

7. Moore TJ, Glenmullen J, Mattison DR. Reports of pathological gambling, hypersexuality, and compulsive shopping associated with dopamine receptor agonist drugs. JAMA Internal Med. 2014;174(12):1930-3.

8. Schade R, Andersohn F, Suissa S, Haverkamp W, Garbe E. Dopamine agonists and the risk of cardiac-valve regurgitation. NEJM. 2007;356(1):29-38.

9. Zanettini R, Antonini A, Gatto G, Gentile R, Tesei S, Pezzoli G. Valvular heart disease and the use of dopamine agonists for Parkinson's disease. NEJM. 2007;356(1):39-46.

10. Trifiro G, Mokhles MM, Dieleman JP, van Soest EM, Verhamme $\mathrm{K}$, Mazzaglia $\mathrm{G}$, et al. Risk of cardiac valve regurgitation with dopamine agonist use in Parkinson's disease and hyperprolactinaemia: a multi-country, nested case-control study. Drug Saf. 2012;35(2):159-71.

11. Adverse Drug Reactions Advisory Committee (ADRAC). Pathological gambling with cabergoline. Aust Adv Drug React Bull. 2005;24(August 2005):15.

12. Adverse Drug Reactions Advisory Committee (ADRAC). Ergot derivatives and fibrotic reactions. Aust Adv Drug React Bull. 2006;25(February 2006):3.

13. Food and Drug Administration. Public Health Advisory-Pergolide (marketed as Permax). 2007. http://www.fdagov/Drugs/ DrugSafety/PostmarketDrugSafetyInformationforPatientsand Providers/ucm051285htm. Accessed 15 Jan 2015.
14. Ooba N, Yamaguchi T, Kubota K. The impact in Japan of regulatory action on prescribing of dopamine receptor agonists: analysis of a claims database between 2005 and 2008. Drug Saf. 2011;34(4):329-38.

15. Perez-Lloret S, Bondon-Guitton E, Rascol O, Montastruc JL, French Association of Regional Pharmacovigilance C. Adverse drug reactions to dopamine agonists: a comparative study in the French Pharmacovigilance Database. Mov Disord. 2010;25(12):1876-80.

16. Evans AH, Katzenschlager R, Paviour D, O’Sullivan JD, Appel $\mathrm{S}$, Lawrence AD, et al. Punding in Parkinson's disease: its relation to the dopamine dysregulation syndrome. Mov Disord. 2004;19(4):397-405.

17. Chaudhuri KR, Dhawan V, Basu S, Jackson G, Odin P. Valvular heart disease and fibrotic reactions may be related to ergot dopamine agonists, but non-ergot agonists may also not be spared. Mov Disord. 2004;19(12):1522-3.

18. Serratrice J, Disdier P, Habib G, Viallet F, Weiller PJ. Fibrotic valvular heart disease subsequent to bromocriptine treatment. Cardiol Rev. 2002;10(6):334-6.

19. Champagne S, Coste E, Peyriere H, Nigond J, Mania E, Pons M, et al. Chronic constrictive pericarditis induced by long-term bromocriptine therapy: report of two cases. Ann Pharmacother. 1999;33(10):1050-4.

20. Hazell L, Shakir SA. Under-reporting of adverse drug reactions : a systematic review. Drug Saf. 2006;29(5):385-96.

21. Moses G, McGuire T. Consumer ADR reporting —alive and well in Australia. Uppsala Rep. 2005;31:12-3.

22. Robertson J, Newby DA. Low awareness of adverse drug reaction reporting systems: a consumer survey. Med J Aust. 2013;199(10):684-6.

23. McGuire T, Moses G. Medical Mishap. 'Statins' and muscle symptoms. Aust Prescr. 2005;28(4):102.

24. Medicines Safety Update. Zolpidem: continued reporting of abnormal sleep-related events and amnesia. Aust Prescr. 2012;35(3):99.

25. Peyriere H, Cassan S, Floutard E, Riviere S, Blayac JP, HillaireBuys D, et al. Adverse drug events associated with hospital admission. Ann Pharmacother. 2003;37(1):5-11.

26. Pariente A, Gregoire F, Fourrier-Reglat A, Haramburu F, Moore $\mathrm{N}$. Impact of safety alerts on measures of disproportionality in spontaneous reporting databases: the notoriety bias. Drug Saf. 2007;30(10):891-8. 